\title{
Numerical and Experimental Investigation of Aerodynamics Characteristics of NACA 0015 Aerofoil
}

\author{
Robiul Islam Rubel**, Kamal Uddin**, Zahidul Islam**, M.D. Rokunuzzaman** \\ * Department of Mechanical Engineering, Bangladesh Army University of Science \& Technology, Saidpur Cantonment, \\ Saidpur-5311, Bangladesh \\ **Department of Mechanical Engineering, Rajshahi University of Engineering \& Technology, Rajshahi-6204, Bangladesh \\ (rubel.ruet10@gmail.com, kamaluddin.me10@yahoo.com,jahid10ruet@gmail.com,rzaman.mte@ ruet.ac.bd)
}

\begin{abstract}
*Corresponding Author; Robiul Islam Rubel, Department of Mechanical Engineering, Faculty of Mechanical \& Production Engineering, Bangladesh Army University of Science \& Technology, Saidpur Cantonment, Saidpur-5311, Bangladesh, Tel: +880-1749-399 082, rubel.ruet10@gmail.com
\end{abstract}

Received: 23.12.2016 Accepted: 07.03.2017

\begin{abstract}
An aerofoil is a streamline body. Symmetric aerofoil (NACA 0015) is used in many applications such as in aircraft submarine fins, rotary and some fixed wings. The ultimate objective of an aerofoil is to obtain the lift necessary to keep an airplane in the air. But construction of the blade with proper angle of attack and implementation has significant effect on lift force. Insufficient lift force might cause fail of airplane flying, especially at high speed. Modern technologists use different simulation techniques to avoid costly model testing. But simulation is based on some assumption. Thus practically results are not fully authentic and have a deviation. In this work numerical and experimental investigation of NACA 0015 is studied at different angle of attack (degree) at different velocity of air by determining the forces at every two degrees from $0^{0}$ to $18^{0}$. The experiment is conveyed in a low speed wind tunnel. The numerical analysis is conducted using ANSYS (combined with CFD and FLUENT FLOW). The use of the CFD technology greatly reduces the overall investment and efforts for aerofoil design. CFD method contributes to visualize the flow pattern inside aerofoil and takes less time and comparatively faster than experiment. After completing the experimental, numerical data is compared. Therefore, the objective of this paper is to find the deviation and validation of aerodynamics characteristics of NACA 0015 aerofoil for experimental and numerical method.
\end{abstract}

Keywords CFD fluent flow, Lift and drag force, Experimental analysis, Numerical analysis, Comparison.

\section{Introduction}

An aerofoil is defined as the cross section of a body that is placed in an airstream in order to produce a useful aerodynamic force in the most efficient manner possible. It is an aerodynamic shape moves through air when applied. When it is applied as wing air is split in two streams. Among them one passes above and the other passes below the wing. The wing's upper surface is so shaped that air rushing over the top, speeds up and stretches out. This phenomenon produces a pressure reduction above the wing. Comparatively air flows in straighter line below the wing. Thus speed and air pressure remains the same for the shape [1]. Angle of attack, leading edge, trailing edge, span length, chord length, lift force, drag force and thickness all of them have to be clearly defined and be calculated from geometry of aerofoil [2]. The aerodynamics characteristic of an aerofoil is mainly depended on the flow characteristic [3]. Because a wing which is actually an aerofoil generates lift due to its characteristics shape. Lift acts on the centre of pressure at the perpendicular of relative wind flow where drag is parallel to relative wind flow which opposes the motion of aerofoil. Resultant force with $\mathrm{X}$-axis at the centre of pressure is produced by the pressure difference between upper and lower surfaces. It is experimentally and theoretically noticed that asymmetrical aerofoil generates more lift than the symmetrical aerofoil. This performance will have an impact on the manoeuvrability [4]. The cross 
sections of wings, propeller blades, windmill blades, compressor and turbine blades in a jet engine, hydrofoils, aircraft vertical stabilizers, submarine fins, rotary and some fixed wings are examples of aerofoil [5,6]. The basic geometry of an aerofoil is shown in Fig. 1. Since an aerofoil is stream line body it may be symmetrical or unsymmetrical in shape characterized by its chord length (C), angle of attack $(\alpha)$, and span length (L) [7]. The basic forces on an aerofoil are shown in Fig. 2. The drag force and lift force significantly depends on its geometrical shape [8]. The proper designing of the aerofoil can minimize the produced drag on the aerofoil. The lift on the aerofoil is due to negative pressure created on the upper part of aerofoil [9]. Low Reynolds number aerofoil is important in civilian, technical or military applications. This may include propellers, high-altitude vehicles, sailing aircraft, light or heavy man carrying aircraft, blades of wind turbine, and micro or unman air vehicles (MAVs) [10]. Flow control over aerofoils is primarily directed at increasing the lift and decreasing the drag produced by the aerofoil [11]. Srinivosan et al. [12] studied on an oscillating aerofoil for evaluation of turbulence models for unsteady flows. He works on NACA 0015 aerofoil by using different turbulence models. Results found experimentally have good consistency with Spalart Allmaras turbulence model for lift, drag and moment coefficient. Lianbing's et al. [13] investigated on the performance of wind turbine NACA 0012 aerofoil using FLUENT (CFD) simulation techniques. With the rapid increase in computer performance, computational fluid dynamics (CFD) is possible in three dimensions at reasonably low costs. This can be employed to investigate complex dynamic three-dimensional effects [14]. Bacha et al. [15] works on prediction of drag over two-dimensional aerofoils in case of transitional flow. Chervonenko at el. [16] studied the effect of AOA on the non-stationary aerodynamic characteristics. Ramdenee et al. [17] investigated on modeling of aerodynamic flutter on a NACA 4412 aerofoil with application to wind turbine blades. Johansen [18] worked on the transition of flow from laminar to turbulent in aerofoil. Launder et al. [19] showed the numerical computation of turbulent flows. Kevadiya et al. [20] did 2D analysis and Saraf [21] of NACA 4412 aerofoil blade. By Bensiger et al. [22] CFD analysis of a bi-convex aerofoil was performed at supersonic and hypersonic speed. Turbulence models for the simulation of the flow over NACA 0012 aerofoil was evaluated by Eleni [23]. Low speed wind tunnel experiment is conducted by Şahin [24] et al. and using CFD (FLUENT) the numerical analysis was performed. A comparison was made between results obtained from experiment and numerical analysis. Study determines that, stall angle has dependency on turbulent that occur behind the aerofoil. As result, effect of the stall angle of aerofoil performance was investigated. CFD enable the engineers to see the aerodynamic effect of changing the geometry and to examine the airflow over an automobile or a particular part such as a wing or hood [25]. This work also focuses on Spalart Allmaras turbulence model for at $3 \times 106$ Reynolds number for lift, drag force performance and stall angle. This paper is evaluated for finding the aerodynamics characteristics using CFD method. This method has contributed to visualize the flow pattern inside an aerofoil quickly than experiment.

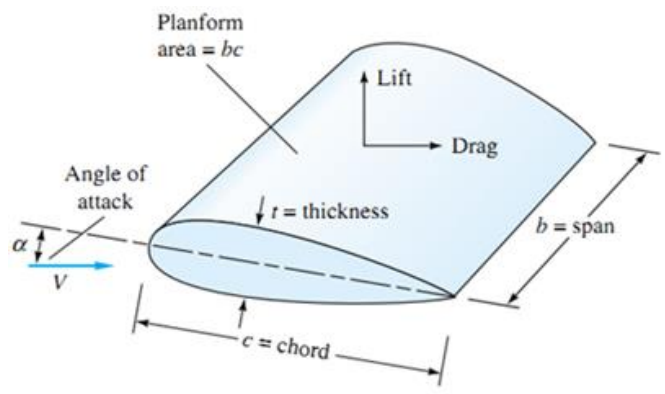

Fig. 1. Geometry of an aerofoil blade.

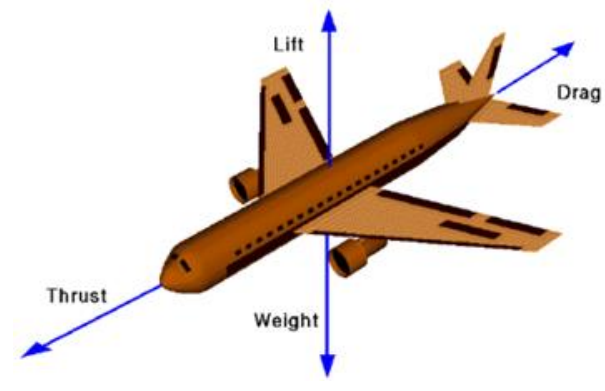

Fig. 2. Forces on a flooding body in air.

Lift and drag force is measured for the projected model of NACA 0015 at different velocity by inclined tube manometer. Lift coefficient $\left(\mathrm{C}_{\mathrm{L}}\right)$, drag coefficient $\left(\mathrm{C}_{\mathrm{D}}\right)$ and drag polar $\left(\mathrm{C}_{\mathrm{L}} / \mathrm{C}_{\mathrm{D}}\right)$ is also measured and compared with experimental results.

\section{Methodology}

The experiment is conducted by an open channel wind tunnel having cross section of $0.3 \mathrm{~m} \times 0.3 \mathrm{~m}$ (aspect ratio 1) and length $0.4 \mathrm{~m}$ at $8.5-9.65 \mathrm{~m} / \mathrm{s}$ wind velocity. The model is first prepared by casting followed by other machining process to obtain desired model. The model is placed in the open wind tunnel having an operating motor of $2800 \mathrm{rpm}$ driving tunnel fan and tested. Lift and drag force are measured from balanced arm and velocity of air determined from inclined tube manometer after placing the model at an angle of attack (2 degree), which is increased after 2 degreeinterval. A model is developed by ANSYS 14.0 workbench modeler and boundary conditions are applied on the aerofoil using FLUENT. A fine mesh body of the airfoil is needed in order to model the flow field accurately. Flow for this Reynolds number can be labeled as incompressible.

\subsection{Experimental Arrangement}

After settling the aerofoil blade specimen (Al) in the shaper machine table, it was feed across the single point cutting tool and removes metal from specimen. For making an aerofoil blade two supporter are needed to support the aerofoil blade. It is also useful for the freely movement of clapper part inside the supporter from top and upper portion. It is very complex to make. Drill bit is feed on the work piece by holding it by bench vise. Drilling operation is done in five 
points on the aerofoil specimen for entering screw in four holes and one hole for pushing small shaft bar which helps to stands the aerofoil blade upon the protractor.
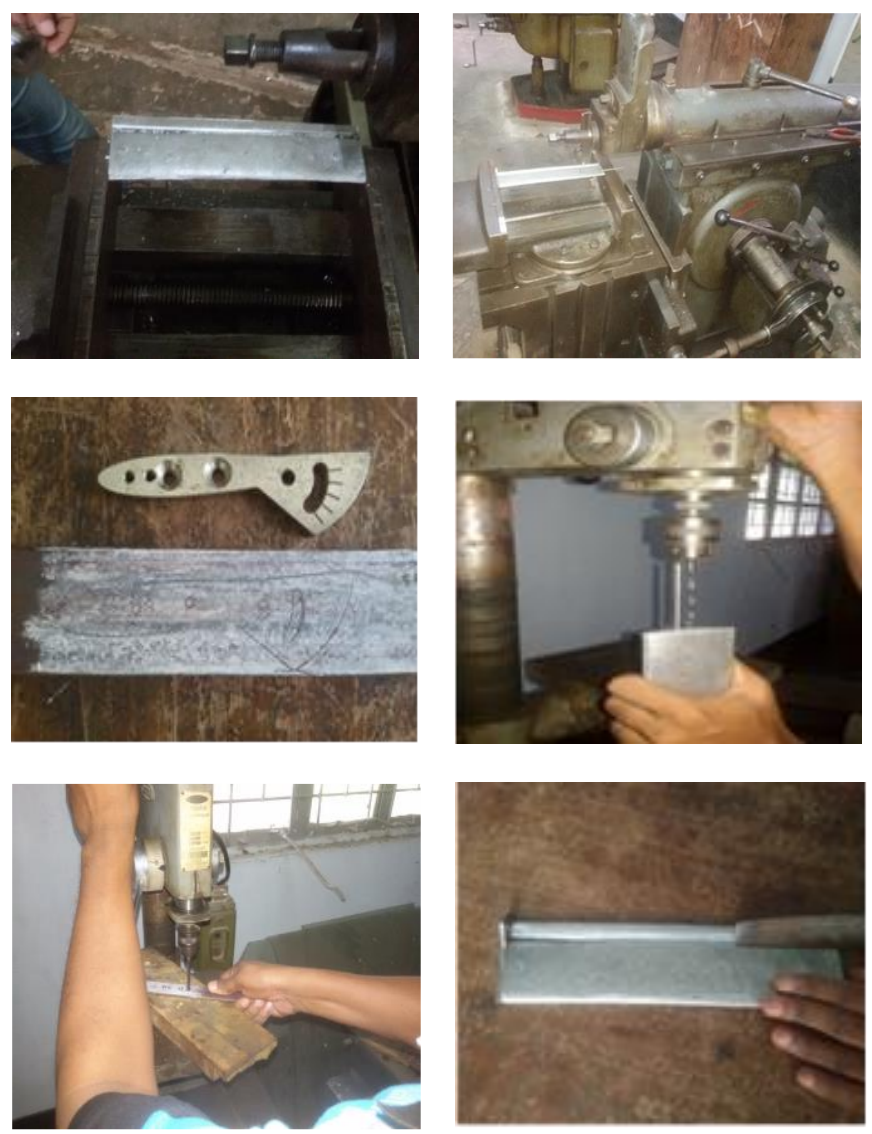

Fig. 3. Preparation of an aluminum NACA 0015 blade.

Additional metal is also removed by using hand grinder. Filling operation is done by using flat file and fine grinding machines, sometimes in machine vise and sometimes in magnetic vice for an operating condition. Figure 3 shows some steps for fabrication of the blade.

Fig. 4 is the diagram of an open type wind tunnel with the following components numbered by (1) Base, (2) Moving carrier, (3) Balance Arm, (4) Speed Controller, (5) Inclined tube manometer, (6,7) Drive section (Motor, fan), (8) Diffuser, (9) Model, (10) Test Section, $(11,13)$ Contraction Cone. The whole setup is shown in Fig. 5.

\section{Theoretical Background}

\subsection{Lift and Drag force}

The force that works normal to the body is referred as lift force. When fluid incorporates a circulatory flow about the body then lift will create as velocity above the object is increased and static pressure is reduced. The slowing of velocity beneath the body gives an increase in static pressure. Consequently, a normal or upwards lift force is created. The drag on a body is also a force as lift force but works in the direction parallel to the flow. Both of them are expressed in dimensionless terms called lift and drag coefficient. Lift force is a component of total force $F$ perpendicular to the stream of Fcos $\alpha$. So for the drag in the direction of the stream, which is Fsin $\alpha$. The lift coefficient $\left(\mathrm{C}_{\mathrm{L}}\right)$ and drag coefficient $\left(\mathrm{C}_{\mathrm{D}}\right)$ is defined as mathematically by Eq. (1) and Eq. (2).

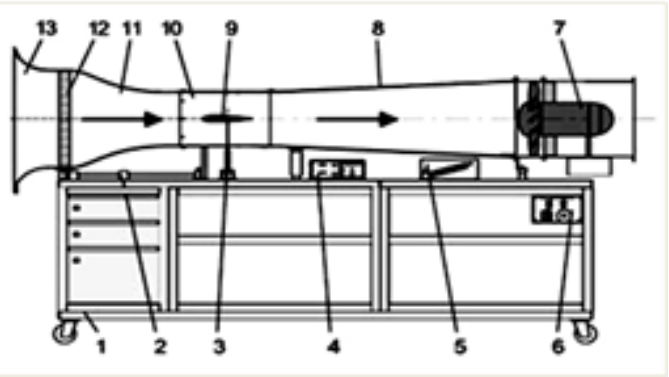

Fig. 4. Diagram of open type wind tunnel.

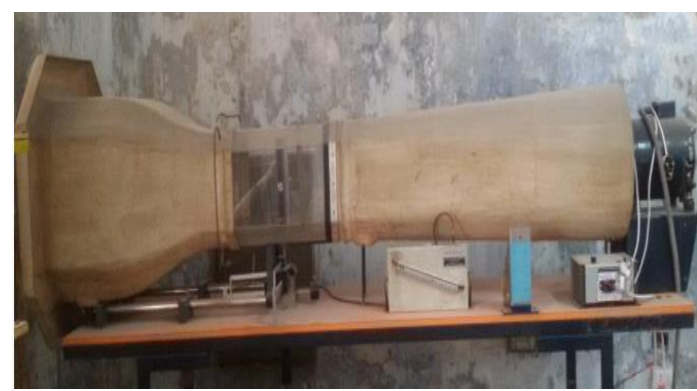

Fig. 5. Experimental setup.

$$
\begin{aligned}
& C_{L}=\frac{2 F_{L}}{\mathrm{pV}^{2} A} \\
& C_{d}=\frac{2 F_{D}}{\mathrm{pV}^{2} A}
\end{aligned}
$$

Where, $F_{L}=$ Lift produced, $F_{D}=$ Drag produced, $\rho=$ density of air, $\mathrm{V}=$ velocity of the air and $\mathrm{A}=(\mathrm{C} \times \mathrm{L})=$ area of the aerofoil. The magnitude of the coefficient differs with the angle of attack. Lift force is high at small angles of attack but drag force is low for a certain angle of attack. After that lift force decreases where drag forces increases.

\subsection{Reynolds number}

The Reynolds number is dimensionless number which is defined as following-

$$
R e_{L}=\frac{\rho V L}{\mu}
$$

Where, density of air $\rho=1.17 \mathrm{~kg} / \mathrm{m}^{3}$, kinematic viscosity, $\mu=1.973 \mathrm{~kg} \cdot \mathrm{m}^{-1} \mathrm{~s}^{-1}$, span length, $\mathrm{L}=26 \mathrm{~cm}$.

\subsection{Mach number}

It is defined as the ratio of the speed of the flow to that of the speed of sound. Again ratio of inertia forces in the fluid to the force resulting from compressibility is also interpreted as Mach number. Mathematically it is written as $\mathrm{M}=\mathrm{U} / \mathrm{a}$. Pressure disturbances propagate through the air at the speed of sound given by $a=\sqrt{r R T^{2}}$. For the experimental set up Mach number $\leq 0.15$. Thus entire range of air flow remains subsonic and incompressible. 


\subsection{Design Criteria}

In this paper, the NACA 0015 aerofoil from the 4-digit series of NACA aerofoil is utilized. The NACA 0015 airfoil is symmetrical is nature. The first two digits ' 00 ' indicate that it has no camber. The ' 15 ' indicates that the airfoil has a $15 \%$ thickness to chord length ratio $(\mathrm{t} / \mathrm{c})$. Ordinates for the NACA 0015 aerofoil can be describe by the following formula.

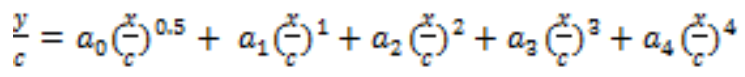

The following co-efficient $\mathrm{a}_{0}, \mathrm{a}_{1}, \mathrm{a}_{2}, \mathrm{a}_{3}$, and $\mathrm{a}_{4}$ are determine to find the required terms. Thus the parameters of the NACA 0015 aerofoil blade are the following-

Chord length of the aerofoil, $\mathrm{C}=0.06 \mathrm{~m}$

Maximum chamber, $\mathrm{m}=$ first digit $\times \% \mathrm{C}=0 \times \frac{1}{100} \times 0.06$

Distance from leading edge to maximum wing thickness, $\mathrm{p}=$ second digit $\times 10 \% \mathrm{C}=0 \times \frac{1}{100} \times 0.06=0$

Maximum wing thickness, $\mathrm{t}=$ last two digit $\times \% \mathrm{C}=$ $15 \times \frac{1}{100} \times 0.06=0.009 \mathrm{~m}$

\subsection{Computational fluid dynamics equations}

The physics of fluid flow are described by equations mathematically. Navier-Stokes equation (Continuity equation and the momentum equation) describe the state of any type of flow and are generally solved for all flows in CFD modeling. Practically the governing equations for flows are complicated. Therefore an exact solution is unavailable and it is necessary to seek a computational solution method. The governing partial differential equations are replaced by algebraic equations in computational technique. The governing equation may have the form like this.

$$
\frac{\partial U}{\partial t}+\frac{\partial F}{\partial x}+\frac{\partial G}{\partial y}+\frac{\partial H}{\partial z}=J
$$

This is also termed as panicking differential equation or a system of equations. They are namely: (a) continuity equation, (b) three dimensional momentum equation, and (e) energy equation. If $\mathrm{U}, \mathrm{F}, \mathrm{G}, \mathrm{H}$. and $\mathrm{J}$ are considered functions with column vector then they take the form given

$$
\begin{aligned}
& U=\left(\begin{array}{c}
\rho \\
\rho u \\
\rho v \\
\rho W \\
\rho\left(e+\frac{V^{2}}{2}\right)
\end{array}\right) \\
& F=\left(\begin{array}{c}
\rho u \\
\rho u^{2}+p-\tau_{x x} \\
\rho w v-\tau_{x y} \\
\rho w u-\tau_{x x} \\
\rho\left(e+\frac{V^{2}}{2}\right) u+p u-h \frac{\partial T}{\partial x}-u \tau_{x x}-v \tau_{x y}-w \tau_{x x}
\end{array}\right)
\end{aligned}
$$

$$
\begin{aligned}
& G=\left(\begin{array}{c}
\rho v \\
p w v-\tau_{y x} \\
\rho v^{2}+p-\tau_{y y} \\
\rho w v-\tau_{y z} \\
\rho\left(e+\frac{V^{2}}{2}\right) w+p v-k \frac{\sigma v}{\partial y}-u \tau_{y x}-v \tau_{y y}-w \tau_{y z}
\end{array}\right) \\
& H=\left(\begin{array}{c}
\rho w \\
p u w-\tau_{x x} \\
\rho w w-\tau_{x y} \\
\rho w^{2}+p-\tau_{z z} \\
\rho\left(e+\frac{W^{2}}{2}\right) w+p w-k \frac{\partial w}{\partial x}-w \tau_{x x}-w \tau_{x y}-w \tau_{x z}
\end{array}\right) \\
& l=\left(\begin{array}{c}
0 \\
\rho f_{x} \\
\rho f_{y} \\
\rho f_{x} \\
\rho\left(u f_{x}+v f_{y}+v f_{x}\right)+q
\end{array}\right)
\end{aligned}
$$

In Eq. (5), the column vectors F, G, and $\mathrm{H}$ are denoted flux terms, and $\mathrm{J}$ represents a source term. The continuity equation can be derived by putting the first vector in Eq. (5).

$$
\frac{\partial \rho}{\partial t}+\frac{\partial \rho u}{\partial x}+\frac{\partial \rho V}{\partial y}+\frac{\partial \rho w}{\partial z}=0
$$

Where ${ }^{\rho}$ stands for density. The mass fluxes in the $\mathrm{x}, \mathrm{y}$, $\mathrm{z}$ directions are ${ }^{\rho u}, \rho v$, and ${ }^{\rho w}$ respectively. The momentum and the energy equation can be found following the same procedure. Both steady state and transient state solutions will be satisfied by Eq. (5). The fluxes considered are (a) mass flux $=^{\rho V}$, (b) flux of $\mathrm{x}, \mathrm{y}$, and $\mathrm{z}$ component of momentum are ${ }^{\rho u V}, \rho v V, \rho w V$, (c) flux of internal energy $=\rho e V$, (d) flux of total energy $={ }^{\rho\left(e+\frac{V^{2}}{2}\right)}$. The CFD codes contain all the necessary equations to be solved. All that is needed is to define computational domain in time and space. Also this need to initialize the solution process by defining the boundary values as a common process in numerical solutions. The computer runs the solution process and solves the required unknowns for each element of fluid or more precisely, for each point in the computational grid.

\section{Results and Discussion}

\subsection{Lift Coefficient and Drag Coefficient vs Angle of Attack}

Lift coefficient depends on angle of attack. The experimental results obtained from our model NACA 0015 are plotted on graph. The Fig. 6 shows that lift coefficient increases with increasing angle of attack and after a certain angle of attack it is decreased and this angle is called stall angle. 


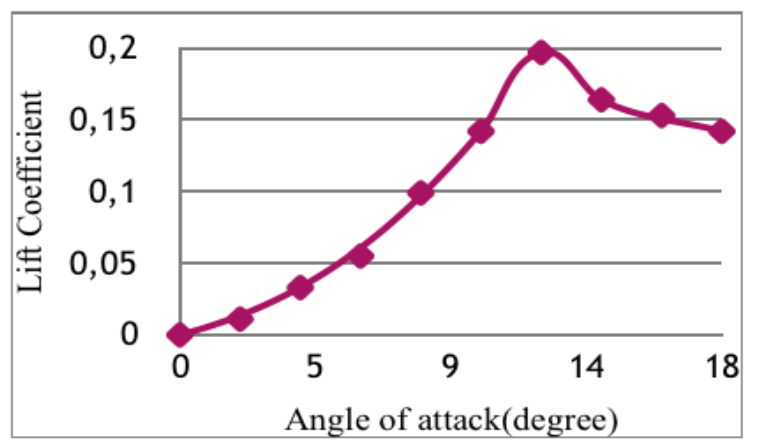

Fig. 6. Variation of Lift Coefficient w.r.to angle of attack.

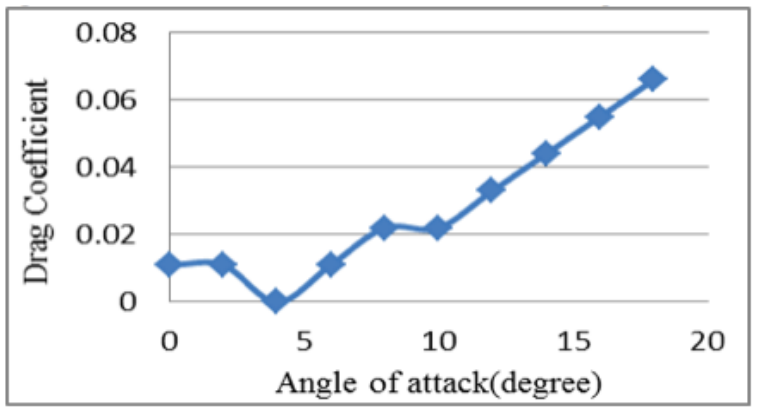

Fig. 7. Variation of Drag Coefficient w.r.to angle of attack.

$\mathrm{C}_{\mathrm{L}}$ is maximum (0.197) at 12 degrees. The stall angle is caused transition from laminar to turbulence flow. Drag coefficient also depends on angle of attack. It is clear from Fig. 7 that the value drag coefficient is increased as angle of attack is increased. Drag coefficient is maximum (0.066) at 18 degrees.

\subsection{Performance curve for NACA 0015}

From Fig. 8 it is clearly noticed that $C_{L} / C_{D}$ is gradually increases as the value of $\mathrm{AOA}$ is increased. $\mathrm{C}_{\mathrm{L}} / \mathrm{C}_{\mathrm{D}}$ is maximum (6.45) at 10 degrees. After these values $C_{L} / C_{D}$ ratio start decreases with the increases of angle of attack.

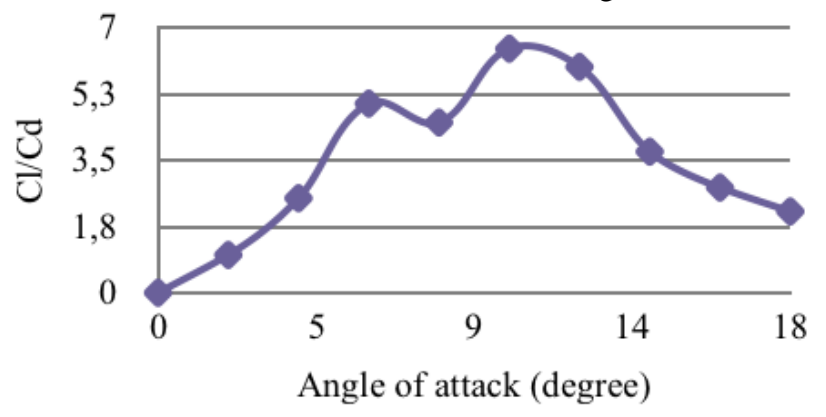

Fig. 8. Variation of $C_{L} / C_{D}$ w.r.to Angle of attack

\section{Simulation with ANSYS and CFD}

\subsection{Problem Specification}

This section shows how to simulate a NACA 0015 aerofoil at different angle of attack placed in a subsonic wind tunnel. FLUENT is used for creating an environment for simulation of this experiment. Afterwards, comparison is made for the values from the simulation and experiment. The coordinates are tabulated from which the following profile is drawn as in Fig. 9 and Fig. 10. In this step the coordinates for NACA 0015 aerofoil were imported to create the geometric shape that will be used for the simulation process.

\subsection{C-Mesh Domain}

After generation of aerofoil profile, it is needed to create the mesh able surface to specify boundary conditions. A coordinate system is created at the tail of the aerofoil to begin C-Mesh. The computational domain is set from tailing edge to inlet and outlet $12.5 \mathrm{~L}$ ( $\mathrm{L}=$ Chord length) $\mathrm{V} 4=$ $=\mathrm{H} 3=\mathrm{R} 5=12.5 \mathrm{~L}$ presented in Fig. 10 where $\mathrm{H} 3=\mathrm{R} 5=12.5 \mathrm{~L}$ presented in Fig. 11.

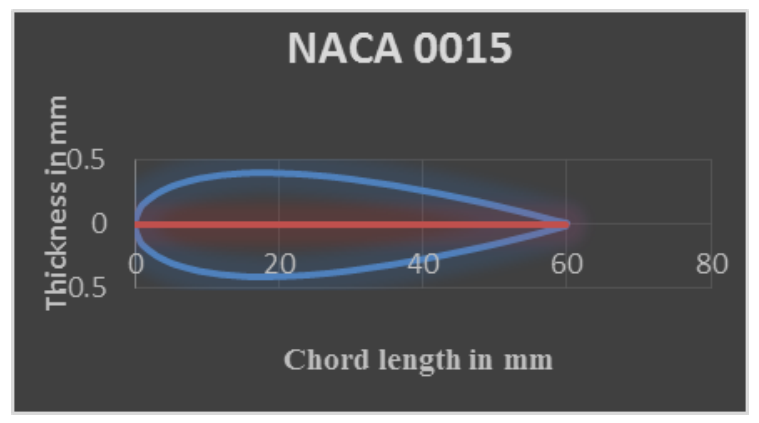

Fig. 9. Aerofoil profile drawn by Microsoft Excel.

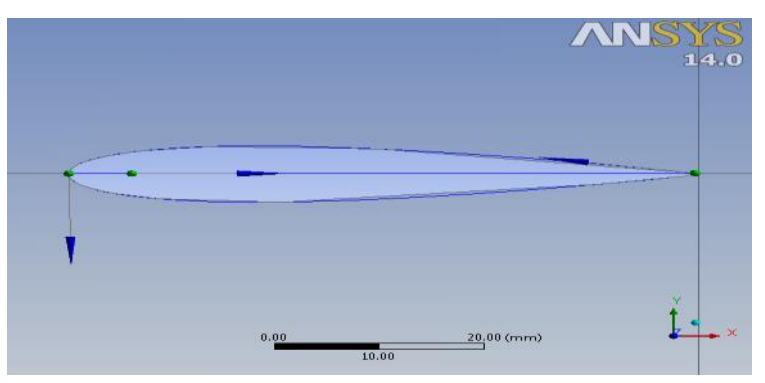

Fig. 10. Geometry of NACA 0015 in ANSYS.

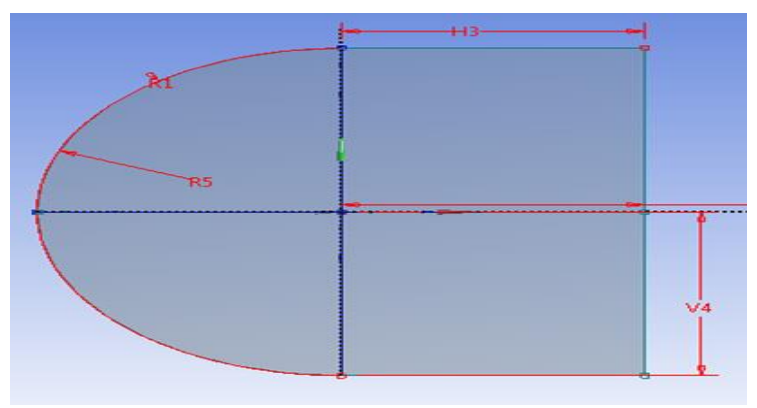

Fig. 11. Setup of a $\mathrm{C}$ mesh domain.

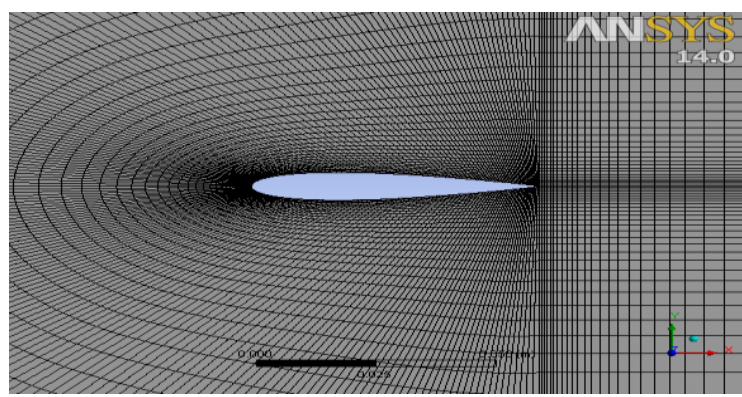

Fig. 12. Mesh generation for NACA 0015. 


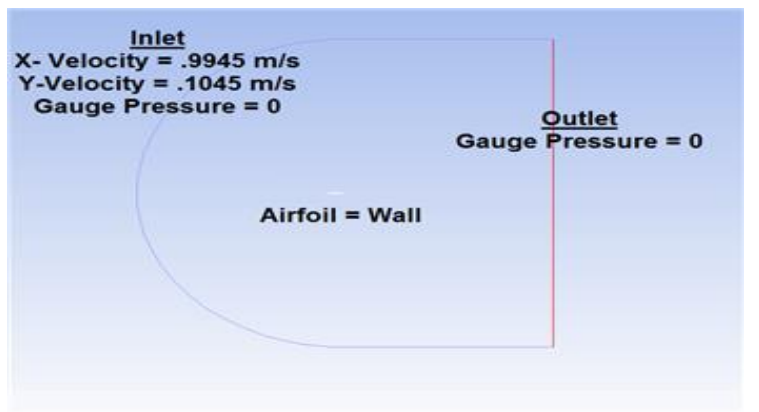

Fig. 13. Setting boundary conditions.

\subsection{Mesh generation}

The flow domain is mandatorily split into smaller subdomains in order to analyze the fluid flows. These are each mesh elements. The mesh mode is shown in Fig. 12. After mesh analysis it is found that total nodes 15300 totals elements 15000 . Mesh analysis was done by assuming relevance center is fine and smoothing is high.

\subsection{Inputs and Boundary condition}

Boundary conditions are a set of physical properties or conditions on surfaces of the domains. The flow simulation is defined completely by the boundary conditions. The equations relating to fluid flow can be closed (numerically) by the specification of conditions on the external boundaries of a domain.

Table 1. Boundary conditions for CFD analysis

\begin{tabular}{|l|c|c|c|}
\hline \multicolumn{1}{|c|}{$\begin{array}{c}\text { Input } \\
\text { Parameter }\end{array}$} & Magnitude & $\begin{array}{c}\text { Input } \\
\text { Parameter }\end{array}$ & Magnitude \\
\hline Solver type & $\begin{array}{c}\text { Density } \\
\text { based }\end{array}$ & AOA & $0^{\circ}-8^{\circ}$ \\
\hline Time & Steady & $\begin{array}{c}\text { Kinematic } \\
\text { viscosity }\end{array}$ & $1.46 \mathrm{e}-5$ \\
\hline $\begin{array}{l}\text { Velocity of } \\
\text { flow }\end{array}$ & $8.5-9.65 \mathrm{~m} / \mathrm{s}$ & $\begin{array}{c}\text { Reynolds } \\
\text { number }\end{array}$ & $\begin{array}{c}\text { Vary with air } \\
\text { velocity }\end{array}$ \\
\hline $\begin{array}{l}\text { Operating } \\
\text { temperature }\end{array}$ & $300 \mathrm{k}$ & $\begin{array}{c}\text { Number of } \\
\text { iteration }\end{array}$ & 1500 \\
\hline $\begin{array}{l}\text { Operating } \\
\text { pressure }\end{array}$ & $1 \mathrm{~atm}$ & $\begin{array}{c}\text { Angle of } \\
\text { Attack }\end{array}$ & $0^{\circ}$ to $18^{\circ}$ \\
\hline $\begin{array}{l}\text { Viscous } \\
\text { model }\end{array}$ & Laminar & $\begin{array}{c}\text { Solution } \\
\text { method }\end{array}$ & $\begin{array}{c}\text { Second order } \\
\text { upwind }\end{array}$ \\
\hline $\begin{array}{l}\text { Density of } \\
\text { fluid(Ideal air) }\end{array}$ & $1.23 \mathrm{~kg} / \mathrm{m}^{3}$ & Length & $0.06 \mathrm{~m}$ \\
\hline
\end{tabular}

Therefore, it is prime important to establish boundary conditions to accurately imitate practical situation that would allow obtaining accurate results. In this work C-mesh is intended to use as it is the most popular mesh for simulating an aerofoil. At the inlet of the system velocity is defined at a 6 degrees angle of attack having total magnitude of one. The gauge pressure at the inlet is defined zero and at outlet the gauge pressure is assumed zero. When all pre-calculations are set, the simulation is ready to perform in ANSYS Workbench. FLUENT is used to simulate completely. The problem considers flow around the Aerospatiale an aerofoil at $0^{\circ}-18^{\circ}$ angles of attack. Some initial inputs and boundary condition for the problems which are set shown in the Table 1 and Fig. 13. Before running the simulation it must configure the software environment according to the following checklists or in other words it classifies the job according to the physical phenomena involved.

\subsection{Results of Simulation}

The following figure shows the result of simulation after completing the total iteration. The analysis is visualized in the following plots.

\subsubsection{Contours of Static Pressure}

Contours of static pressure show that static pressure increases at the lower surface of the aerofoil with increasing angle of attack.

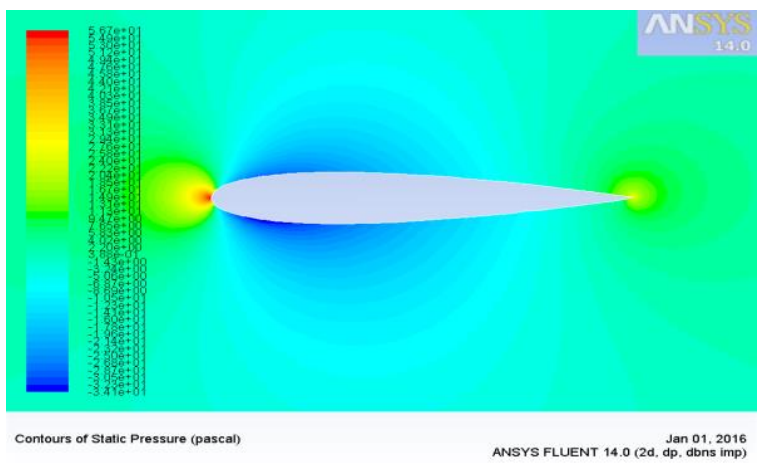

(a) 0 degrees angle of attack

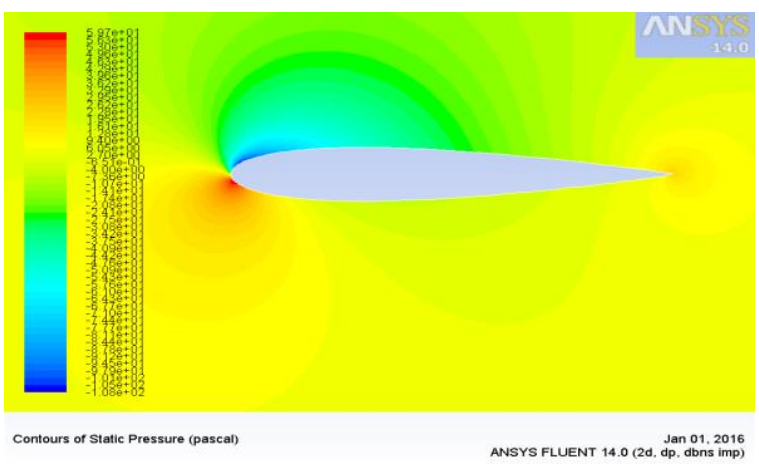

(b) 6 degrees angle of attack

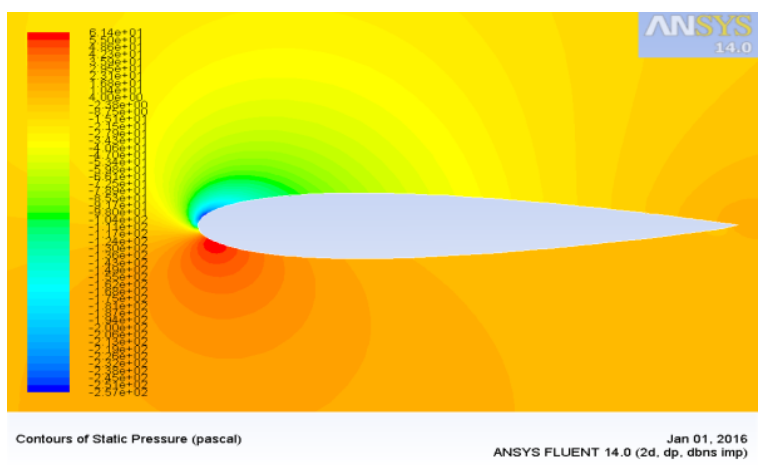

(c) 12 degrees angle of attack 


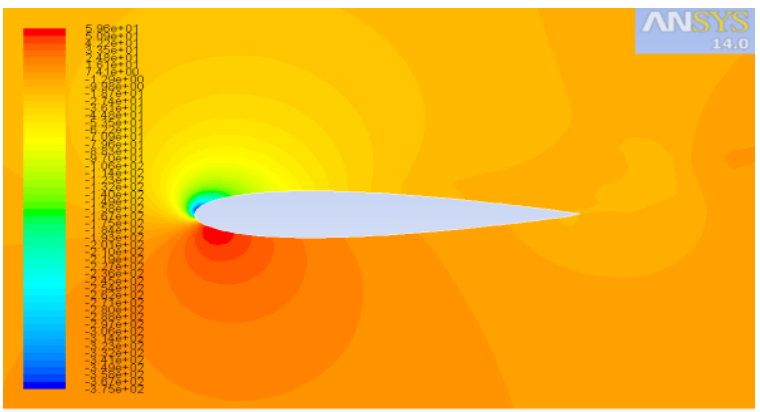

Jan 01,2016
ANSYS FLUENT 14.0 (2d, dp. dbrs imp)

(d) 18 degrees angle of attack

Fig. 14. Static Pressure contours for NACA 0015.

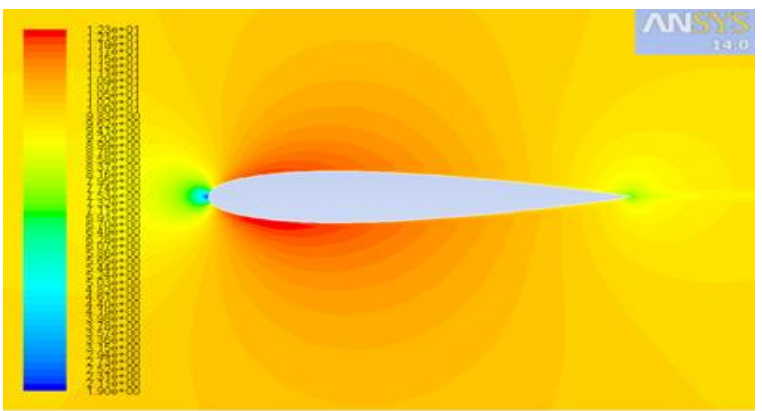

ANSYS FLUENT 14.0 (20, Jap. 01, 201,2016

(a) 0 degrees angle of attack

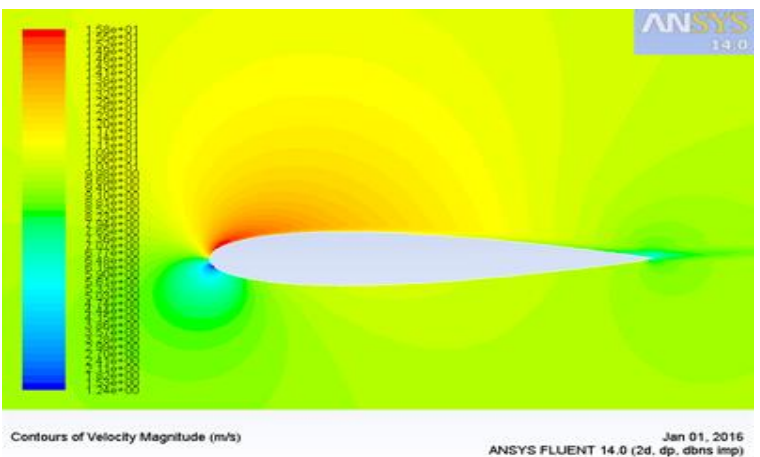

(b) 6 degrees angle of attack

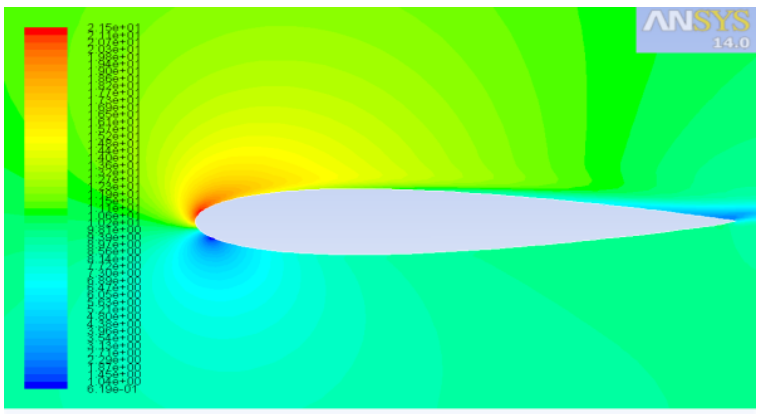

ANSYS FLUENT 14.0 (2d. dpan. dibns imp)

(c) 12 degrees angle of attack

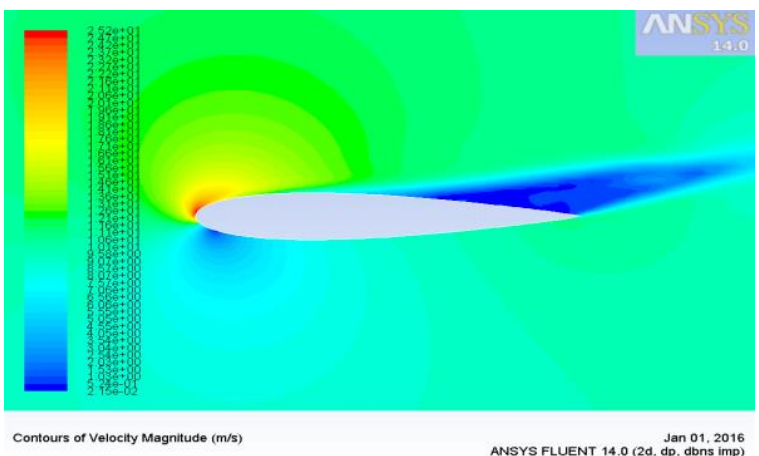

(d) 18 degrees angle of attack

Fig. 15. Contours of velocity magnitude for NACA 0015.

Fig. 14 shows the outcomes of static pressure at angles of attack $0^{\circ}-18^{\circ}$ with the viscous model. It is depicted from the figure that, magnitude of pressure on the aerofoil is more in lower surface than that of the incoming flow stream. As a result an effective upward push called lift is obtained, perpendicular to the incoming flow stream. Static pressure increases with increasing angle of attack but at 12 degrees angle (Maximum $6.14 \mathrm{e}=01 \mathrm{~Pa}$ ) of attack it decreases slightly. Between $0^{\circ}$ to $12^{\circ}$ angle of attack flow pattern is laminar around the NACA 0015 airfoil. Laminar flow becomes go through transition turbulence flow for more than $16^{\circ}$ AOA. Therefore, pressure distribution also changed and lift coefficient began to decrease.

\subsubsection{Contours of Velocity Magnitude}

Contours of velocity magnitude show that static pressure increases at the lower surface of the aerofoil with increasing angle of attack but reversely velocity magnitude increases at the upper surface. Contours of velocity components at angles of attack $0^{\circ}-18^{\circ}$ are also shown in Fig. 16. The stagnation point at the trailing edge moves slightly forward at low AOA. At stall angle it jumps rapidly to the leading edge. Higher velocity is experienced in the upper surface compare to lower surface and increase with AOA as expected from the nature of pressure distribution. The Fig. 16(a) demonstrates that leading edge of NACA 0015 experiences higher static force than telling edge. It is clearly noticed from the Fig. 16(b) that velocity at the upper surface is increased than lower surface of the aerofoil. Low velocity at lower surface generates more lift.

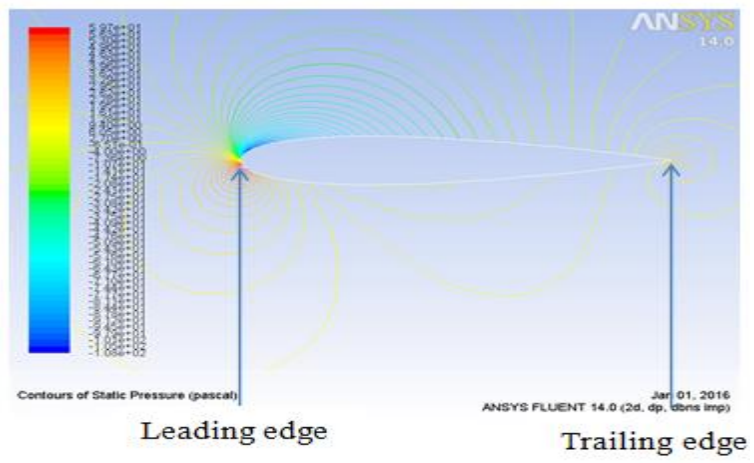

(a) 


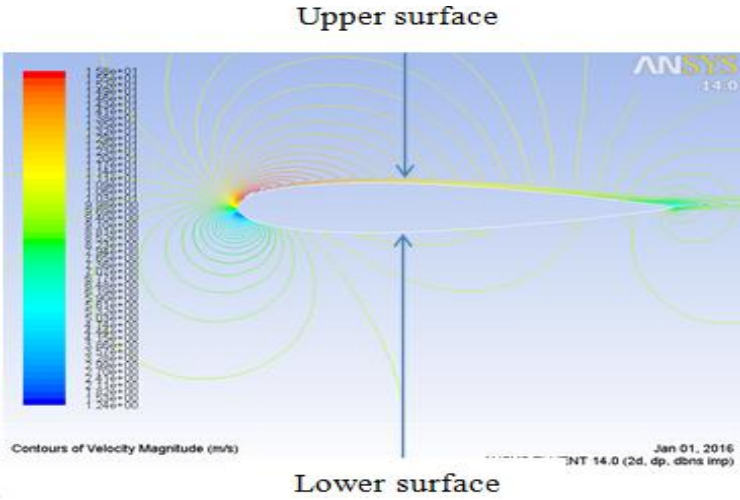

(b)

Fig. 16. At $6^{\circ}$ angle of attack (a) Static pressure contours without filled, (b) Velocity magnitude contours without filled for NACA 0015.

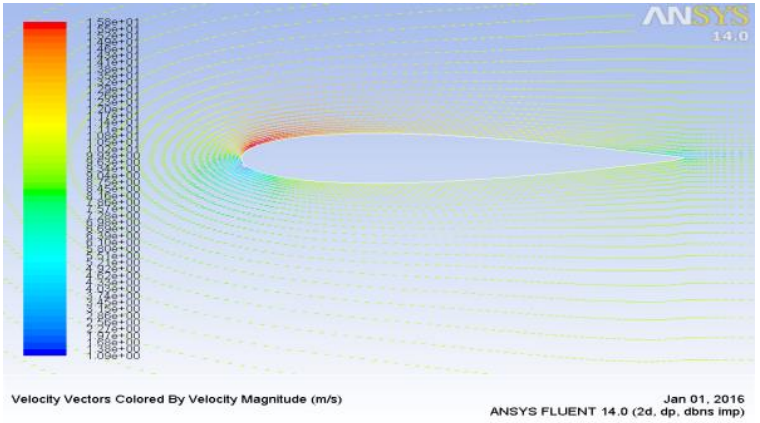

Fig. 17. Velocity vector colored by velocity magnitude.

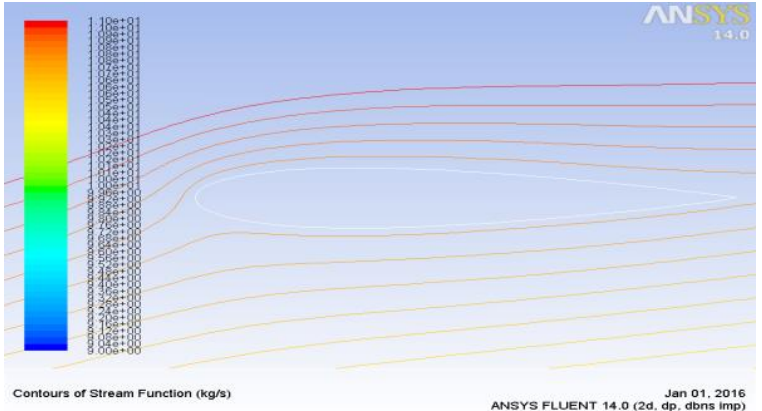

Fig. 18. Stream function for NACA 0015.

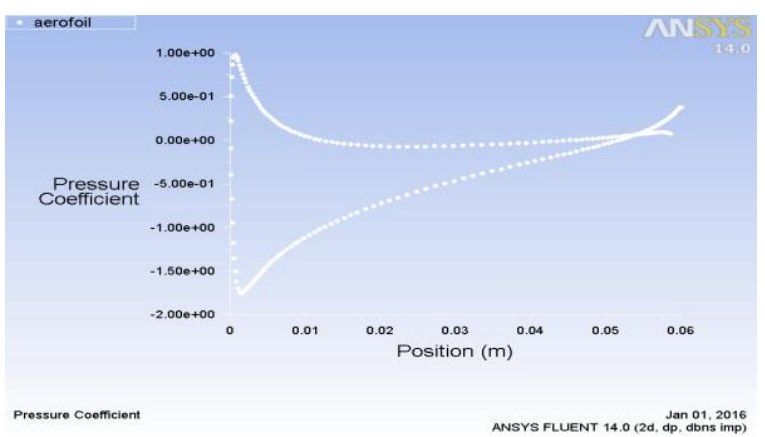

Fig. 19. Pressure coefficient vs position of chord length curve for NACA 0015.

\subsubsection{Velocity Vector and Stream Function at $6^{\circ}$ Angle of Attack}

After analysis it is found that velocity vector is $15.8 \mathrm{~m} / \mathrm{s}$ for NACA 0015. The pressure distribution parallel to the stream line of the incoming flow tends to slow the velocity of the incoming flow presented in Fig. 17 and Fig 18. Pressure Coefficient vs Position of Chord Length curve at $6^{\circ}$ angle of attack is presented in Fig. 19. The two curves show that negative pressure at the lower surface of the aerofoil is greater than positive surface.

It is clearly observed from Fig. 20 (a) that pressure coefficient is very low experienced only at leading edge of the aerofoil due to its lower angle of attack. Fig. 20(b) shows that with increasing angle of attack, the area between positive $\mathrm{Cp}$ and negative $\mathrm{Cp}$ is increased and this high pressure coefficient generates lift on the airfoil to turn around or to fly. Further angle of attack is increased $\left(12^{\circ}\right), \mathrm{Cp}$ is increased at the lower surface of the aerofoil greater than $6^{\circ}$ angle of attack which shown at contours of pressure coefficient also at the area of graph shown in Fig 20(c).
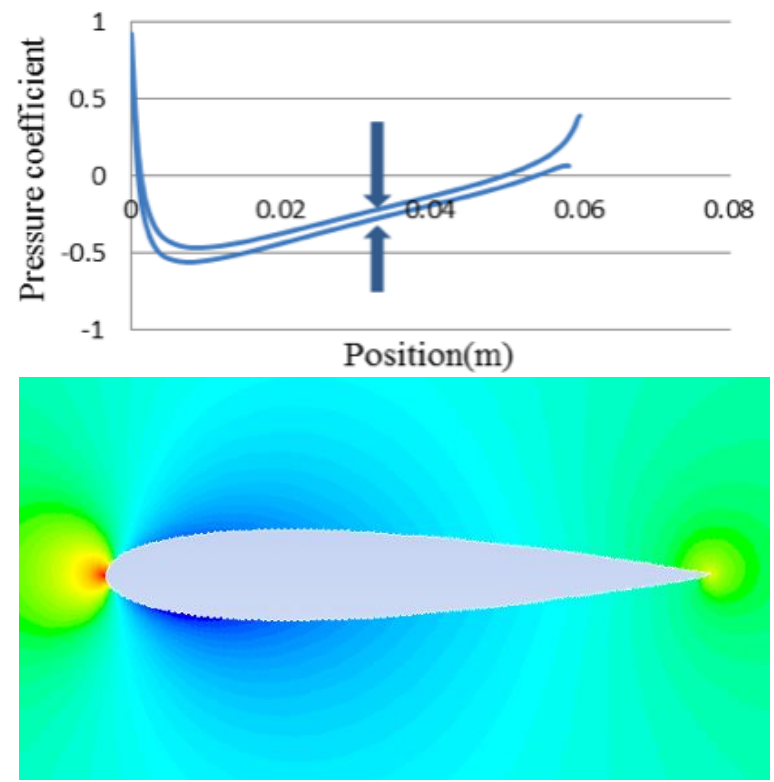

(a) $0^{\circ}$ angle of attack
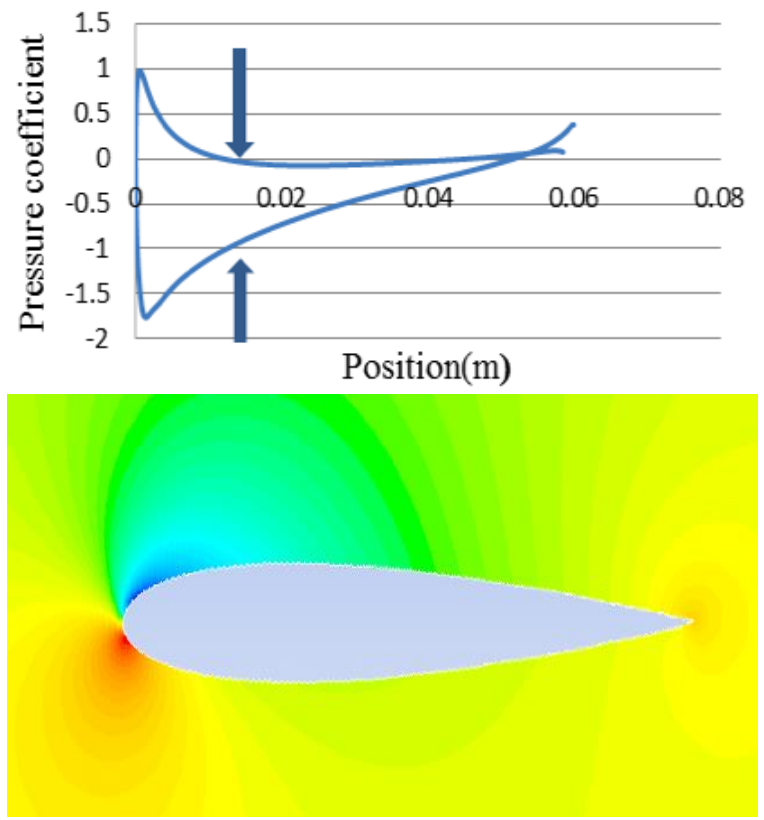

(b) $6^{\circ}$ angle of attack 

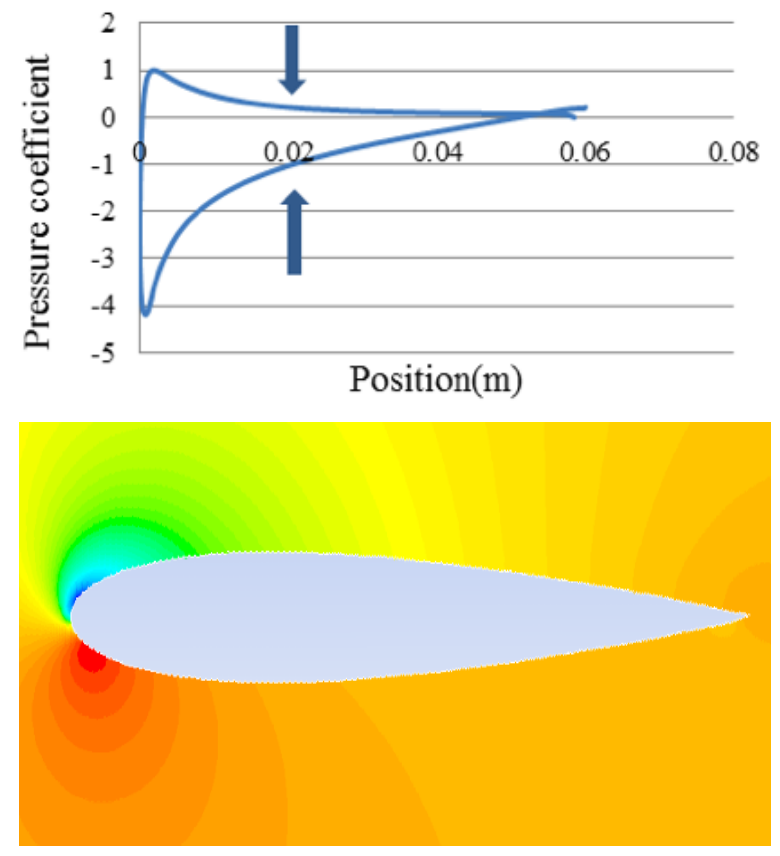

(c) $12^{\circ}$ angle of attack

Fig. 20. Pressure coefficient $(\mathrm{Cp})$ vs position of chord length (m) and contours of pressure coefficient for NACA 0015 at different AOA.

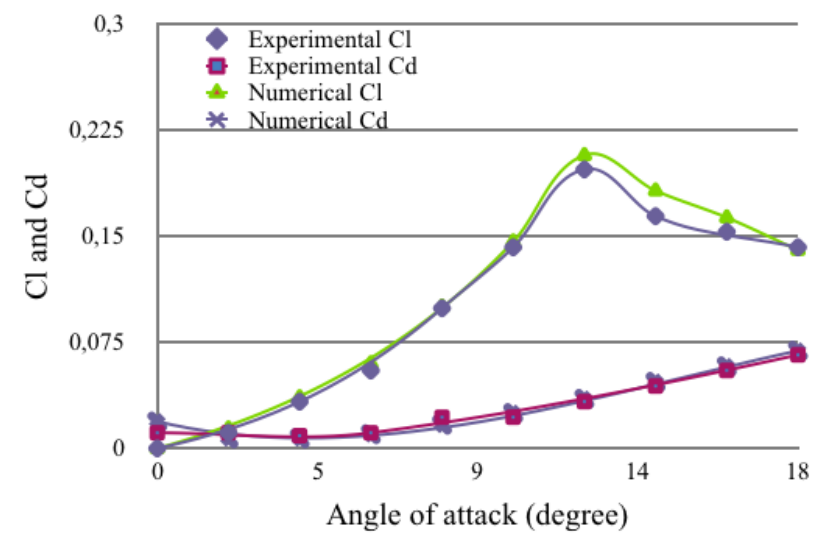

Fig. 21. Variation of $C_{L}$ and $C_{D}$ w.r.to angle of attack.

\section{Comparison of the Experimental and Numerical Data}

Fig. 21 is the comparable curve between numerical and experimental data. In Fig. 21 it is seen that lift coefficient increases with the increases of angle of attack up to a certain limit then it decreases experimentally but numerically lift coefficient stay some nearer to the value obtained from experimentally. Drag coefficient increases with the increases of angle of attack experimentally and also numerically value of drag coefficient remains very closest. It is shown in the above figure that lift coefficient is 0.197 for NACA 0015 numerically which is very closer to the value obtained in experimentally 0.207 .

\section{Conclusions}

Preparing a NACA 0015 aerofoil blade, experimental and numerical measurement of lift and drag force is performed. The experiment is compensated for NACA 0015 by an open type wind tunnel. CFD study of airfoils is performed to predict its lift and drag characteristics, visualization and surveillance of flow field pattern around the body. It shows distribution of turbulence, distribution of pressure and total pressure velocity contour around NACA 0015 aerofoil blade. Both lift and drag coefficient increases as angle of attack (degree) is increased. The drag coefficient gradually is decreased as Reynolds's number increases. But with the increase of Reynolds's number lift coefficient increases slightly and after a certain point it decrease. There is large negative pressure created on the aerofoil, which accounts for most of the lift. Pressure is maximum and velocity is zero at stagnation point. Distinct red point on the velocity contour plots characterized this zone. With positive AOA, stagnation point transfers in the direction of trailing edge on the lower surface of the aerofoil. This deviation of pressure between upper and lower surface of the airfoil principally creates significant amount of positive lift. Numerical modeling can be good practice for determining the aerofoil properties instead of costly wind tunnel model tests.

\section{Acknowledgement}

The authors gratefully thanks to Prof. Dr. Mohammad Rafiqul Islam, Department of Mechanical Engineering, RUET, Bangladesh, for allowing the use of wind tunnel placed in fluid mechanics lab, support and guidance. Greatly thanks to Prof. Dr. Rokunuzzaman, Head of the Department of Mechatronics Engineering, RUET, Bangladesh, for his instructive supervision during experimental investigation. In addition the authors gratefully acknowledge to Rajshahi University of Engineering and Technology owing to allowing use of machine shop lab and necessary help to make NACA 0015 aerofoil blade model.

\section{References}

[1]K. S. Patel, S. B. Patel, U. B. Patel, and A. P. Ahuja, "CFD Analysis of an Aerofoil", International Journal of Engineering Research, vol. 3, issue. 3, pp. 154-158, March 2014.

[2]I. B. Llorca, "CFD Analysis and Assessment of the Stability and Control of a Supersonic Business Jet", Royal Institute of Technology (KTH), Stockholm, Sweden, March 2015.

[3]Y. T. Chuen, M. Z. Abdullah, and Z. Husain, "The Effects of Turbulence Intensity on the Performance Characteristics of NACA 0015 and Eagle 150 Airfoils", Proc. NSF Seminar 2002.

[4]W. L. Siauw, J. P. Bonnet, and J. Tensi, "Physics of Separated Flow Over a NACA 0015 Airfoil and Detection of Flow Separation", 47th AIAA Aerospace Sciences Meeting Including The New Horizons Forum and Aerospace Exposition, 5 - 8 January 2009, Orlando, Florida.

[5]M. R. Islam, M. A. Hossain, M. N. Uddin, and M. Mashud, "Experimental Evaluation of Aerodynamics 
Characteristics of a Baseline Aerofoil", American Journal of Engineering Research, vol. 4, Issue. 1, pp. 91-96, 2015.

[6]S. Kandwal, and S. Singh, "Computational Fluid Dynamics Study of Fluid Flow and Aerodynamic Forces on an Aerofoil", International Journal of Engineering Research \& Technology, vol. 1, Issue. 7, 2012.

[7]Dr. R. K. Bansal, Fluid Mechanics and Hydraulic Mechunes, 9th ed., Laxmi Publication (P) Ltd, 2010, pp. 686- 687.

[8]M. Morshed, S. B. Sayeed, S. A. A. Mamun, and J. Alam, "Investigation of Drag Analysis of Four Different Profiles Tested at Subsonic Wind Tunnel", Journal of Modern Science and Technology, vol. 2, No. 2, pp. 113-126, 2014. (Article)

[9]E. H. Lewitt, Hydraulics and Fluid Mechanics, 10th ed., Sir Isaac Pitman \& Sons Ltd, 1963, pp. 382-383.

[10] M. S. Selig, and J. J. Guglielmo, "High-Lift Low Reynolds Number Airfoil Design", Journal of Aircraft, vol. 34, No. 1, 1997.

[11] Z. Yang, H. Igarashi, M. Martin, and Hui Hu, “An Experimental Investigation on Aerodynamic Hysteresis of a Low-Reynolds Number Aerofoil", American Institute of Aeronautics and Astronautics, AIAA-2008-0315, 2008.

[12] G. R. Srinivasan, J. A. Ekaterinaris, and W. J. McCroskey, "Evaluation of Turbulence Model for Unsteady Flows of an Oscillating Aerofoil", Elsevier Science Ltd., Computers \& Fluids, vol. 24, No. 7, 1995, pp. 833-861.

[13] L. B. Li, Y. W. Ma, and L. Liu, "Numerical Simulation on Aerodynamics Performance of Wind Turbine Aerofoil", Conf. on World Automation Congress (WAC), Puerto Vallarta, Mexico, Publisher by IEEE, pp. $1-4,2012$.

[14] M. Gaunaa, J. N. Sørensen, P. S. Larsen, "Unsteady Aerodynamic Forces on NACA 0015 Airfoil in Harmonic Translatory Motion", Technical University of Denmark, (MEK-FM-PHD; No. 2002-02, 2002.

[15] W. Bacha, and W. Ghaly. "Drag Prediction in Transitional Flow Over Two-Dimensional Airfoils", 44th AIAA Aerospace Sciences Meeting and Exhibit, Aerospace Sciences Meetings, Reno, Nevada, 2006.

[16] A. G. Chervonenko, "Effect of attack Angle on the Nonstationary Aerodynamic Characteristics and Flutter
Resistance of a Grid of Bent Vibrating Compressor Blades", Ukrainian Academy of Sciences, Plenum Publishing Corporation, Ukraine, vol. 39, No. 10, pp. 7881. 1991.

[17] D. Ramdenee, H. Ibrahim, N. Barka, and A. Ilinca, "Modeling of Aerodynamic Flutter on A NACA 4412 Airfoil Wind Blade", International Journal of Simulation and Process Modeling, Inderscience Publishers, Canada, vol. 8, No. 1, pp. 79-87, 2013.

[18] J. Johansen, "Prediction of Laminar/Turbulent Transition in Airfoil Flows", Journal of Aircraft, Aerospace Research Central, Denmark, vol. 36, No. 4, pp. 731-734, 1997.

[19] B. E. Launder, and D. B. Spalding, "The Numerical Computation of Turbulent Flows", Computer Methods in Applied Mechanics and Engineering, vol. 3, No. 2, pp. 269-289, 1974.

[20] M. Kevadiya, H. A. Vadiya, "2D Analysis of NACA 4412 Airfoil", International Journal of Innovative Research in Science Engineering and Technology, vol. 2, No. 5, pp. 168-1691, 2013.

[21] A. K. Saraf, M. Singh, and A. Kumar, "Analysis of the Spalart-Allmaras and k- $\omega$ standard models for the simulation of the flow over a National Advisory Committee for Aeronautics (NACA) 4412 airfoil", International Journal of Scientific \& Engineering Research, vol. 3, Issue 8, pp. 1-7, August-2012.

[22] S. S. B. Bensiger, and N. Prasanth, "Analysis of BiConvex Airfoil Using CFD Software at Supersonic and Hypersonic Speed", Elixir International Journal, vol. 53, pp. 11695-11698, 2012.

[23] D. C. Eleni, T. I. Athanasios, and M. P. Dionissios, "Evaluation of the Turbulence Models for the Simulation of the Flow over an Aerofoil", Journal of Mechanical Engineering Research, vol. 4, No. 3, pp. 100-111, 2012.

[24] I. Şahin, and A. Acir, "Numerical and Experimental Investigations of Lift and Drag Performances of NACA 0015 Wind Turbine Aerofoil', International Journal of Materials, Mechanics and Manufacturing, vol. 3, No. 1, pp. 22-25, 2015.

[25] S. Chandra, A. Lee, S. Gorrell, and C. G. Jensen, "CFD Analysis of PACE Formula-1 Car", ComputerAided Design \& Applications, PACE (1), 2011, 1-14. 